\title{
Allergic Rhinitis, Asthma, and Rhinosinusitis: Diseases of the Integrated Airway
}

\author{
ELI O MeLTZeR, MD; JAVIER SZWARCBERG, MD, MPH; and MICHAEL W. PILL, PharmD
}

\begin{abstract}
OBJECTIVE: To review data supporting the integrated airway hypothesis. Allergic rhinitis, rhinosinusitis, and asthma are common conditions associated with significant morbidity and health care costs. A theory has been developed suggesting that these conditions may be manifestations of an inflammatory process within a continuous airway rather than fully separate diseases. Based on this theory, the presence of upper airway symptoms may negatively influence the natural course of lower airway disease. Controlling upper airway inflammation and symptoms among asthma patients may help improve health and economic outcomes.
\end{abstract}

SUMMARY: Further clarifying and understanding the relationship between diseases of the upper and lower respiratory tracts is important because of the prevalence of allergic rhinitis, rhinosinusitis, and asthma and the resulting burden on patients and the health care system. Recent progress in understanding the biology of airway disease has identified inflammation as playing a critical and integrating role in these diseases; however, other important questions remain, including factors that determine the clinical phenotype in allergic airway disorders and optimal treatment approaches.

CONCLUSIONS: Several recent studies have suggested that allergic rhinitis, rhinosinusitis, and asthma may be manifestations of a common underlying pathology, but there are many unanswered questions. More studies are needed to better define all the underlying pathologic mechanisms as well as treatments to optimize outcomes for patients with allergic rhinitis, rhinosinusitis, and asthma.

KEYWORDS: Allergic rhinitis, Asthma, Rhinosinusitis, Integrated airway, Inflammation

J Manag Care Pharm. 2004;10(4):310-17 $\square$ iseases of the respiratory tract represent one of the most common reasons patients seek medical attention in the United States. In 2000, approximately 1 in 8 physician office visits were attributable to diseases of the respiratory system. ${ }^{1}$ Allergic rhinitis, rhinosinusitis, and asthma comprise a substantial proportion of these visits, and each condition has a significant impact on quality of life and the direct and indirect costs associated with medical care. Given the burden of allergic rhinitis, rhinosinusitis, and asthma, it is of concern that their prevalence has increased substantially over the past 20 to 30 years. $^{2}$

Allergic rhinitis, rhinosinusitis, and asthma are frequently comorbid conditions, and this association has been recognized since the early 1900s. Recent studies have strengthened the concept that allergic rhinitis, rhinosinusitis, and asthma are manifestations of an inflammatory process within a continuous airway. Although the key component of this concept is inflammation, various additional mechanisms that link the upper (nose, sinuses, larynx, pharynx, and trachea) and lower (bronchi and lungs) airway segments are possible and not yet completely understood. Still, the integrated airway hypothesisoften referred to as the united airway disease, the chronic respiratory inflammation syndrome, ${ }^{3}$ or rhinosinobronchitisis widely appreciated and is supported by findings from numerous studies. ${ }^{3-6}$ If validated, the integrated airway hypothesis might have significant clinical implications for the management of patients with allergic rhinitis or asthma. The purpose of this article is to review the data that suggest a link between upper (e.g., allergic rhinitis, rhino-sinusitis) and lower airway (e.g., asthma) disorders.

\section{Burden of Allergic Rhinitis, Asthma, and Rhinosinusitis}

A relationship between allergic rhinitis, rhinosinusitis, and asthma is a relevant issue because of the prevalence of these diseases and the impact their symptoms have on direct and indirect health care costs.

Although allergic rhinitis is frequently regarded as a nuisance illness, it is, in fact, associated with substantial morbidity and health care costs. Allergic rhinitis affects more than 50 million Americans, and the result is 9 million physician office visits each year. ${ }^{1,7,8}$ In the year 2000 , more than $\$ 6$ billion was spent on prescription medications alone. ${ }^{8}$ Blanc et al. ${ }^{9}$ found that, over a 12-month period, the proportion of study patients with rhinitis who sought medical attention at emergency departments or urgent care centers (38\%) was similar to that for patients with asthma (37\%). 
Indirect costs of allergic rhinitis include lost work productivity, reduced performance and learning, and increased traffic accidents. ${ }^{10}$ Certainly, the effects of rhinitis symptoms have an effect on work productivity and performance; however, the actual impact is difficult to determine because most studies addressing this issue utilize a methodology in which patients self-report the diagnosis, severity of symptoms, work status, and impact on productivity and performance. For example, in the Blanc study, ${ }^{9}$ which involved random-digit telephone dialing to recruit patients, approximately $70 \%$ of patients selfreported their symptoms/condition as being moderate or severe. Patients with asthma had a lower rate of employment than did those with rhinitis (88\% versus $97 \%$, respectively; $P=.002$ ), but self-reported absentee rates attributed to the respective conditions were similar among patients with asthma and rhinitis. Approximately 1 in 4 self-reported 1 or more partial or complete lost work days within the preceding month.

Productivity estimates from a National Health Interview Survey $^{11}$ indicated that absenteeism and reduced productivity resulting from symptoms of allergic rhinitis total more than $\$ 600$ million. Although rhinitis symptoms have a significant effect on work performance and productivity, the side effects of sedating antihistamines have a more pronounced effect. Additional at-work productivity losses of nearly $\$ 5$ billion resulted from the effects of sedating antihistamines.

Asthma affects approximately 20.3 million Americans and, in 2000, accounted for 9.3 million physician office visits, 1 million hospital outpatient visits, 1.8 million emergency room visits, and 478,000 hospitalizations. ${ }^{1,12}$ As is the case for allergic rhinitis, asthma is associated with substantial morbidity. In recent surveys, $84 \%$ of patients admit that asthma has had a negative impact on their lives, ${ }^{13}$ and $30 \%$ of patients with asthma report nighttime awakening with breathing problems at least once a week. Overall, 14.5 million lost work days and 14 million lost school days each year have been attributed to asthma ${ }^{1}$, and patients with asthma have had, on average, $75 \%$ more sick days compared with the general population. ${ }^{14}$ Unlike allergic rhinitis, however, asthma exacerbations can be lethal. In 2000, asthma led to the death of approximately 4,500 patients. ${ }^{1}$ Recent estimates of the health care costs associated with asthma total nearly $\$ 14$ billion per year, with more than $\$ 9.4$ billion attributable to direct costs and more than $\$ 4.6$ billion to indirect costs. ${ }^{1}$

In a recent analysis of claims data, ${ }^{15}$ the direct costs of treating one or more comorbid respiratory diseases was greater than the direct costs of treating allergic rhinitis or asthma alone. Total direct costs (outpatient, inpatient, emergency room, pharmacy) for patients with allergic rhinitis alone were $\$ 287$ an episode. Patients in this database had an average of 1.2 episodes a year, with annual costs averaging $\$ 344$. In contrast, costs for patients with allergic rhinitis and concomitant asthma were more than $50 \%$ higher ( $\$ 436$ per episode, or $\$ 523$ annually). Higher total costs for patients who had concomitant allergic rhinitis and rhinosinusitis were also greater as compared with patients with allergic rhinitis alone (\$334 per episode). In each of these cases, the cost drivers were outpatient and pharmacy charges.

Because standard diagnostic criteria are lacking, the true prevalence of acute rhinosinusitis is unknown, but sinusitis is considered one of the 10 most common diagnoses in the ambulatory setting, accounting for $\$ 3.9$ billion in total health care costs in the United States in 1996. ${ }^{16}$ An estimated 1 billion cases of viral respiratory infections occur each year in the United States. ${ }^{17}$ Although approximately $90 \%$ of these cases will have evidence of sinus involvement, ${ }^{16,17}$ the vast majority represent self-limiting viral infections. Secondary bacterial infections are believed to complicate approximately $0.5 \%$ to $2 \%$ of viral respiratory infections, resulting in up to 20 million cases of acute bacterial rhinosinusitis. ${ }^{16}$

\section{Prevalence of Concomitant Allergic Rhinitis, Asthma, and Sinusitis}

Several cross-sectional studies have demonstrated that allergic rhinitis, asthma, and rhinosinusitis frequently coexist, despite methodologic limitations such as lack of precise, standardized criteria for diagnosis of rhinitis; differentiation between allergic and nonallergic rhinitis; and consistency in using biologic criteria (e.g., skin tests). ${ }^{18-20}$ Up to $40 \%$ of patients with allergic rhinitis suffer from asthma, which is considerably higher than the 5\% to $10 \%$ prevalence of asthma in the general population. The prevalence of allergic rhinitis among patients with asthma is as high as 90\% - when rigorous diagnostic criteria for rhinitis are used $^{4,21,22}$ - which is significantly higher than the $20 \%$ prevalence rate in the general population. ${ }^{23}$

Radiographic studies conducted over the past few decades have shown that $40 \%$ to $60 \%$ of patients (children and adults) with asthma have abnormal sinus radiographs, ${ }^{4}$ and in patients with moderate or severe asthma, the magnitude of sinus symptoms and computed tomographic scan abnormalities is greater than in those individuals with mild asthma. ${ }^{24}$ In a recent analysis of medical claims data, ${ }^{15}$ it was noted that approximately $18 \%$ of patients with rhinitis had concomitant asthma, and nearly $40 \%$ of patients with asthma had concomitant rhinitis. Allergic rhinitis also may be a contributing factor in 25\% to $30 \%$ of patients with acute maxillary sinusitis and in as many as $60 \%$ to $80 \%$ of patients with chronic sinusitis. ${ }^{19}$ At the least, allergic rhinitis is associated with, and probably a predisposing factor in the development of, rhinosinusitis. ${ }^{25}$ In a recent analysis of medical claims data, ${ }^{15} 26 \%$ of patients with sinusitis had concomitant allergic rhinitis and $11 \%$ of patients with sinusitis had concomitant asthma.

Longitudinal studies consistently indicate a relationship between allergic rhinitis and asthma-patients with allergic rhinitis have a 3-fold higher risk of developing asthma later in life. ${ }^{22,26}$ In general, the more persistent and severe the rhinitis, 
the more likely the association with asthma. ${ }^{26}$ Although asthma frequently occurs concomitantly in many patients with sinusitis, the association is most likely attributable to the relationship between rhinitis and asthma, but formal population studies have not evaluated sinusitis as an independent risk factor for asthma.

Although prevalence studies provide valuable information on the frequency of allergic rhinitis, rhinosinusitis, and asthma (as comorbid conditions) and the temporal relationship between them, these studies cannot validate or refute the integrated airway hypothesis. Nevertheless, population studies indicate that the relationship between upper and lower airway disorders is more than coincidence alone.

\section{Links Between Allergic Rhinitis, Rhinosinusitis, and Asthma}

There are many common anatomic pathophysiologic features between upper and lower airway disorders, primarily in histology and immunology. Examples of common anatomic features include ciliated columnar cell epithelial lining, mucinous glands, vasculature, and innervation. Regarding pathophysiology, both asthma and allergic rhinitis exhibit a similar early allergic response characterized by vasodilation and increased vascular permeability and mucus production. Upper and lower airway disorders also exhibit similar characteristics of chronic inflammation, including infiltration of leukocytes, and the involvement of eosinophils, lymphocytes, macrophages, mast cells, cytokines, leukotrienes, and other inflammatory mediators. ${ }^{27}$

The anatomic connection between the upper and lower airways suggests a possible role of nasal drippings in eliciting bronchial hyperreactivity in patients with allergic rhinitis or rhinosinusitis. ${ }^{28}$ In one study, radiolabeled aerosol used to deliver allergen intranasally could not be detected in the lower airways, suggesting that allergen deposited in the upper airways did not seed the lower airways. However, allergens and inflammatory mediators may be absorbed systemically from the nasal mucosa and affect the lower airways. ${ }^{29}$

An early study ${ }^{30}$ investigating the integrated airway hypothesis suggested a nasobronchial reflex arc as a potential mechanism linking upper and lower airway disorders. Based on this hypothesis, nasal allergen challenge affects bronchial hyperresponsiveness through a reflex arc that involves trigeminal afferents and vagal efferents. Most of the studies evaluating the existence and role of a nasobronchial reflex arc were not able to demonstrate changes in lower airway hyperresponsiveness (forced expiratory volume in 1 second $\left[\mathrm{FEV}_{1}\right]$, response to methacholine) following allergen challenge to the upper airways. But, when patients with allergic rhinitis and mild asthma were studied, allergen challenge to the nasal mucosa resulted in bronchial hyperresponsiveness in approximately $20 \%$ to $30 \%$ of subjects.

Another potential mechanism linking allergic rhinitis, rhinosinusitis, and asthma is a systemic inflammatory response that occurs following local allergen challenge. Inflammation is a common component of the allergic response for both allergic rhinitis and asthma, and inflammation has been clearly demonstrated in experimental models involving nasal and bronchial allergen challenge. ${ }^{31}$ Furthermore, eosinophils and mast cells play a key role in both allergic rhinitis and asthma. ${ }^{32-35}$ Several studies have documented the presence of eosinophils in the upper airways of asthmatics without nasal symptoms and in the lower airways of patients with allergic rhinitis who do not exhibit bronchial hyperreactivity or other signs of asthma. ${ }^{36-38}$

Gaga et al. ${ }^{37}$ compared the presence of eosinophils in nasal mucosal biopsies obtained from patients with comorbid asthma and allergic rhinitis, asthma without allergic rhinitis, and healthy subjects. The number of eosinophils in nasal biopsies from patients with asthma was approximately 4-fold higher compared with those from healthy subjects $(P<.01)$. There was no statistically significant difference in the number of eosinophils between the 2 groups of asthmatics. Bronchial biopsies also were obtained from some patients with asthma, and there was a strong correlation between the number of eosinophils in nasal and bronchial samples $(r=.851, P<.001)$.

In a study by Braunstahl et al., ${ }^{38}$ patients with grass polleninduced allergic rhinitis but without a history of asthma underwent segmental endobronchial allergen challenge with grass pollen. At the time of allergen challenge, study participants had a normal $\mathrm{FEV}_{1}$ and a $\mathrm{PC}_{20}$ methacholine of $>8 \mathrm{~g} / \mathrm{mL}$, confirming that asthma was not present in these patients. Endobronchial and nasal mucosal biopsies were obtained at baseline and 24 hours after allergen challenge. Within 24 hours, the number of eosinophils in nasal mucosal biopsies increased approximately 2 -fold following allergen challenge $(P>0.05)$. Using a visual analog scale, the investigators also demonstrated an increase in pulmonary and nasal symptoms during the follow-up assessment. The investigators concluded that the inflammatory response following allergen challenge is not restricted to a local effect. However, it is important to note that the number of eosinophils recruited at the site of allergen challenge was approximately 20-fold higher in bronchial samples compared with nasal mucosal samples.

However, the common finding of eosinophils in upper and lower airways following local allergen challenge is insufficient, in itself, to explain the connection between asthma and allergic rhinitis. Polosa et al. ${ }^{39}$ observed patients with allergic rhinitis who underwent bronchial challenge with methacholine and adenosine monophosphate to assess bronchial hyperresponsiveness and inflammatory response. Although patients with allergic rhinitis had an increased number of eosinophils in induced sputum following challenge compared with nonallergic controls, sputum eosinophilia was not associated with bronchial response (i.e., hyperresponsiveness) to methacholine.

Despite the strong correlation between allergic rhinitis and asthma, some patients with allergic rhinitis never develop asthma (and vice versa), and the reasons for this are still unclear. Although nonspecific subclinical bronchial hyperreactivity is common in many patients with allergic rhinitis ${ }^{26,40-42}$ it is 
not known what causes certain patients to progress to clinically apparent asthma over time. The appearance of asthma symptoms may depend on the extent of allergen exposure (e.g., amount, duration); therefore, patients with allergic rhinitis but without clinically apparent asthma may require a greater extent of allergen exposure to elicit overt signs and symptoms of asthma. The mechanism of bronchoconstriction in patients with asthma also may be different from that in patients with allergic rhinitis. In one study, ${ }^{43} 17$ patients ( 8 with allergic rhinitis alone and 9 with mild asthma alone) underwent methacholine and allergen inhalation challenges. Bronchoalveolar lavage and bronchial biopsy were performed prior to and after allergen challenge. The investigators demonstrated that the inflammatory response to inhaled allergen challenge in the bronchi of patients with allergic rhinitis was similar to that of patients with asthma. However, an important finding from this study was that the methacholine dose required to elicit bronchoconstriction was significantly lower in patients with asthma than in patients with allergic rhinitis, which suggests a different mechanism for bronchoconstriction.

\section{Therapeutic Implications}

Although allergic rhinitis, rhinosinusitis, and asthma have historically been regarded and treated as distinct disorders, observational data suggest that controlling nasal symptoms often substantially improves asthma symptoms and health care resource utilization. ${ }^{4-48}$ Similarly, failing to reduce inflammation in the upper airways may lead to suboptimal results in asthma treatment. ${ }^{7}$ However, determining whether these disorders truly influence the natural course of each other or whether the treatments influence a common underlying pathogenic mechanism is more difficult.

The data are compelling that controlling nasal symptoms with intranasal steroids improves asthma symptoms and nonspecific bronchial hyperreactivity.,33,49-52 In fact, intranasal administration of beclomethasone to patients with allergic rhinitis has been shown to have a more pronounced effect on bronchial hyperresponsiveness compared with a similar dose administered via oral inhalation. ${ }^{51}$ Patients included in this study had no prior history of asthma, a normal physical examination, and normal spirometry findings; however, they all had bronchial hyperresponsiveness to inhaled carbachol. ${ }^{51}$ In another study, nasal and chest symptoms were assessed in patients with seasonal allergic rhinitis and asthma following treatment with intranasal steroids, cromolyn, or placebo. ${ }^{48}$ Rhinitis scores in patients improved with active treatment, and asthma symptoms were virtually eliminated in the groups receiving intranasal steroids but less among those receiving cromolyn and least in placebo-treated subjects. ${ }^{48}$ Additionally, Watson et al. ${ }^{52}$ reported that bronchial hyperresponsiveness to methacholine was significantly reduced in patients with perennial allergic rhinitis and asthma following treatment with intranasal steroids but not fol- lowing intranasal placebo. More importantly, the investigators also performed a radiolabeled deposition study of intranasal steroid administration and found that less than $2 \%$ was deposited in the chest area. These results suggest that the improvement in asthma symptoms was the result of improved nasal function or reduced nasal inflammation and not a direct effect of the intranasally administered corticosteroid on the lower airways.

Until recently, there has been limited information on the clinical relevance of controlling nasal symptoms in patients with asthma. Two recent observational studies evaluated the effects of treating allergic rhinitis (in patients with allergic rhinitis and asthma) on emergency department visits or hospitalizations for asthma. ${ }^{44,45}$ The study by Adams et $\mathrm{al}^{44}$ was a retrospective cohort analysis involving members of a large managed care organization. More than 13,800 patients with a diagnosis of asthma (children and adults) were tracked for 3 years. Patients with asthma who received nasal steroids had a 30\% lower risk of asthma-related emergency department visits compared with those who did not receive such treatment. This finding was consistent among children and adults and was independent of the use of oral inhaled steroids for controlling asthma. ${ }^{44}$ In this study, the investigators observed that daily treatment for allergic rhinitis was not necessary to observe a benefit for asthma outcomes. Patients who received 3 inhaled nasal steroid prescriptions per year had a 50\% lower risk of asthma-related emergency department visits compared with 30\% for those who received at least 1 prescription per year.

Crystal-Peters et al. ${ }^{45}$ similarly employed a retrospective cohort design to evaluate the effects of treatments for allergic rhinitis on asthma-related health care resource utilization. In this analysis, the risk of an acute asthma-related event (emergency department visit or hospitalization) was approximately 50\% lower for patients treated with nasal steroids or oral antihistamines compared with those who did not receive these treatments. In this study, patients who received treatment for allergic rhinitis also received a significantly higher number of medications for asthma. Such a finding has led some to suggest that treatment with inhaled nasal steroids or oral antihistamines may be a marker of the quality of asthma management. ${ }^{53}$ However, in multivariate analyses, controlling allergic rhinitis symptoms still correlated with improved asthma outcomes.

Despite the fact that intranasal steroids are the most effective agents for controlling symptoms of allergic rhinitis, second generation antihistamines are sometimes regarded as first-line therapy for this disorder. ${ }^{7}$ In the analysis of medical claims data, second generation antihistamines were used in nearly $35 \%$ of allergic rhinitis episodes compared with $28 \%$ for inhaled nasal steroids. ${ }^{15}$ In mice, treatment with fexofenadine prevented lower airway inflammation responses to allergen challenge, as indicated by decreased eosinophils, lymphocytes, and cytokine production. ${ }^{54}$ In addition, although second generation antihistamines have been documented to be valuable and are indicated 
TABLE 1 Disease Characteristics Before and After Sinusitis Treatment in 48 Children $^{66}$

\begin{tabular}{l|c|c}
\hline & \multicolumn{2}{|c}{ Number of Patients n/N (\%) } \\
\hline Characteristic & Before & After \\
\hline Cough & $48 / 48(100)$ & $14 / 48(29)$ \\
\hline Wheeze & $48 / 48(100)$ & $7 / 48(15)$ \\
\hline Normal pulmonary function test & $0 / 30(0)$ & $20 / 30(67)$ \\
\hline Bronchodilator treatment & $48 / 48(100)$ & $10 / 48(21)$ \\
\hline
\end{tabular}

for managing allergic rhinitis, they have also been shown to improve pulmonary symptoms in patients with concomitant asthma. ${ }^{19,44,46,47,55-57}$

In a study by Grant et al., ${ }^{46} 186$ patients with allergic rhinitis and mild-to-moderate asthma were randomized to treatment with cetirizine (10 mg daily) or matching placebo for a 6-week treatment duration. Nasal and asthma symptoms were selfassessed twice daily and pulmonary function was assessed (peak flow measurement) weekly. Pseudoephedrine $(30 \mathrm{mg}$ every 6 hours) was allowed as rescue medication for control of nasal symptoms, and albuterol (as needed) was used to control asthma symptoms. Oral theophylline was continued for those patients who were on a stable dose prior to study entry. At the end of the 6-week treatment period, patients treated with cetirizine had a more favorable self-assessment of nasal and asthma symptoms compared with placebo-treated patients. Although there was no statistically significant difference between the 2 treatment groups on pulmonary function (i.e., peak flow measurements), patients treated with cetirizine used less albuterol compared with placebo-treated patients. These findings suggest that oral antihistamines can improve nasal and asthma symptoms but that other inflammatory pathways must be targeted to improve pulmonary function.

Corren et al. ${ }^{47}$ evaluated the effects of loratadine (5 mg twice daily) plus pseudoephedrine (120 mg twice daily) in 184 patients with allergic rhinitis and mild asthma. Patients were instructed to use albuterol on an as-needed basis for control of asthma symptoms, but no other asthma or rhinitis medications were allowed. Patients were treated for 6 weeks, during which nasal and asthma symptoms were self-assessed daily. Pulmonary function also was assessed on a daily basis. Nasal and asthma symptom scores were significantly lower among patients treated with loratadine/pseudoephedrine compared with those receiving placebo throughout the entire 6-week study period. Pulmonary function also improved significantly in the active-treatment group, but only during weeks 2 through 6 of the study period. Albuterol was used sparingly by both treatment groups throughout the study, although there was a trend toward less albuterol use among patients treated with loratadine/pseudoephedrine.
The results of other studies evaluating the effects of oral antihistamines demonstrated that doses higher than those recommended for allergic rhinitis were required for beneficial effects on asthma symptoms. ${ }^{58}$ Despite their potential benefits, antihistamines are not, as yet, generally prescribed for the management of asthma. Further evidence suggests that using antihistamines to treat children with atopy may reduce the subsequent onset of asthma. ${ }^{59}$

Leukotrienes are powerful chemoattractants for eosinophils, and a recent review article gave support to the idea that leukotrienes play an important role in upper and lower airways disease.$^{60}$ In one study, leukotriene levels from nasal lavage were compared in patients with allergies to ragweed pollen and nonallergic patients. ${ }^{61}$ Leukotriene levels in allergic patients increased in a dose-dependent manner following allergen challenge, whereas nonallergic patients did not exhibit symptoms or evidence of leukotriene release. Although leukotriene receptor antagonists provide modest improvements in allergic rhinitis symptoms, ${ }^{62}$ the available data do not clearly address whether these agents offer additional benefit over existing agents, particularly in the absence of concomitant asthma. ${ }^{63} \mathrm{~A}$ study by Wilson et al..$^{64}$ compared the effects of treatment with a leukotriene receptor antagonist plus an oral antihistamine with intranasal and inhaled corticosteroids for patients with allergic rhinitis and asthma. Both combination regimens improved asthma symptom scores and pulmonary function and reduced the need for rescue inhaler use compared with baseline. The findings from this study strengthen the link between allergic rhinitis and asthma (based on common mediators and inflammatory properties), but clearly demonstrate that more information is needed on how these medications achieve efficacy.

There are data that also suggest that controlling sinus mucosal inflammation in patients with rhinosinusitis appears to improve the clinical assessment of asthma symptoms. The treatment of rhinosinusitis medically or surgically improves asthma symptoms in most patients to such an extent that the amount and type of asthma medication can be reduced. ${ }^{5}$

In cases of bacterial rhinosinusitis, antibiotic therapy may be helpful in controlling nasal mucosal inflammation. ${ }^{65}$ Rachelefsky et al. ${ }^{66}$ evaluated the effects of treatment with antibiotics followed by antral lavage (in some cases) in school age children with at least a 3-month history of sinusitis and active (daily) wheezing (Table 1). Children were excluded from the study if they had a documented elevation in body temperature within the preceding 3 weeks or if they received antibiotic treatment within the preceding 4 weeks or nasal corticosteroids. Twenty-two (46\%) of the children had no prior chronic respiratory symptoms, but, at the time of enrollment, all children were treated with oral bronchodilator (theophylline), 10 received cromolyn sodium, and 18 received oral corticosteroids in the preceding 12 weeks. Asthmatic medications were continued during antibiotic therapy. Following 2 to 5 weeks of antibiotic 
therapy, nearly $80 \%$ of the children were able to discontinue bronchodilator use, and $67 \%$ had pulmonary function tests that returned to the normal range. Study participants were followed for only 3 months after the completion of antibiotic therapy, and no information is available on the duration that study participants remained symptom-free and objectively well. The results of another study suggest that antibiotic treatment may improve asthma symptoms, as evidenced by the response to bronchodilator therapy ${ }^{67}$ Eight patients with an acute exacerbation of asthma (despite continued bronchodilator therapy) were included in this study. All patients had radiographic evidence of sinusitis, and 5 had positive bacterial cultures from maxillary sinus aspirates. Following 14 to 28 days of antibiotic therapy, pulmonary function tests improved in 7 patients, including all those with positive bacterial cultures. Compared with baseline, there was approximately a 2-fold increase in the response to bronchodilator therapy (maximum midexpiratory flow rate and $\mathrm{FEV}_{1}$ ) following the completion of antibiotic therapy (Table 2). Importantly, in this study, patients were also treated with pseudoephedrine, oxymetazoline, bronchodilators (theophylline, $\beta$-adrenergic agents), and corticosteroids (4-day course in 4 patients). The use of these other treatments makes it difficult to fully determine the effects of antibiotic therapy on pulmonary function.

Intranasal administration of corticosteroids can reduce nasal inflammation, nasal congestion, and bronchial hyperreactivity. These agents are often included in the treatment regimen for patients with rhinosinusitis. ${ }^{5}$ The analysis of medical claims data revealed that while antimicrobial therapy is used in $82 \%$ of rhinosinusitis episodes, newer antihistamines are used in only $20 \%$ of episodes and intranasal corticosteroids in $13 \%$ of episodes..$^{15}$ Surgical treatment for sinusitis also has been reported to improve asthma symptoms $\mathrm{s}^{68,69}$; however, methodologic limitations (i.e., lack of control group) complicate the interpretation and application of this finding.

\section{Summary and Conclusions}

Further clarifying and understanding the relationship between diseases of the upper and lower respiratory tracts is important because of the prevalence of allergic rhinitis, rhinosinusitis, and asthma; their impact on patients' lives; the resultant burden on the health care system; and the potential benefits of an integrated management approach. Recent progress in understanding the biology of airway disease has identified that systemic inflammatory responses play a critical and integrating role in these diseases, but other important questions remain, such as optimal integrated treatment approaches. Prospective, randomized, controlled studies are needed to better define the effects that treatments for allergic rhinitis have on asthma morbidity and health care costs. Cost-effectiveness analyses also may help identify the best treatment approaches that will lessen the burden to the health care system associated with these prevalent respiratory illnesses.

\begin{tabular}{|c|c|c|c|c|c|c|}
\hline & \multicolumn{3}{|c|}{ Before Antibiotics } & \multicolumn{3}{|c|}{ After Antibiotics } \\
\hline & $\operatorname{Pre}^{*}$ & Post $^{\dagger}$ & Change & $\mathrm{Pre}^{*}$ & Post $^{\dagger}$ & Change \\
\hline MMEFR (mean) & 57 & 66 & 16 & 59 & 80 & 36 \\
\hline $\mathrm{FEV}_{1}$ (mean) & 93 & 101 & 8 & 101 & 116 & 15 \\
\hline $\begin{array}{l}\text { * Prebronchodilator. } \\
\text { † Postbronchodilator. }\end{array}$ & \multicolumn{6}{|c|}{$\begin{array}{l}\text { MMEFR = maximum midexpiratory flow rate. } \\
F E V_{1}=\text { forced expiratory volume in } 1 \text { second. }\end{array}$} \\
\hline
\end{tabular}

\section{DISCLOSURES}

Funding for this study was provided in part by a grant from Aventis Pharmaceuticals, which was obtained by The MCM Group. Author Eli O.

Meltzer has received grant/research support from and served as a consultant to numerous pharmaceutical companies; he discloses no bias or conflict of interest. Author Javier Szwarcberg is employed by Aventis, and author Michael W. Pill discloses no financial interest or affiliation with Aventis. Meltzer served as principal author of the study. Study concept and design, analysis and interpretation of data, and drafting of the manuscript and its critical revision were the work of all authors.

\section{REFERENCES}

1. Cherry DK, Burt CW, Woodwell DA. National Ambulatory Medical Care Survey: 2000 summary. Advance Data. 2001;328:1-32.

2. Altemeier WA, Graff GR. How are allergic rhinitis and sinusitis connected with asthma? Pediatr Ann. 2000;29:391-92, 398.

3. Togias A. Rhinitis and asthma: evidence for respiratory system integration. J Allergy Clin Immunol. 2003;111:1171-83.

4. De Benedictis FM, Miraglia del Guidice M, Severine S, Bonifazi F. Rhinitis, sinusitis and asthma: one linked airway disease. Pediatr Respir Rev. 2001;2: 358-64.

5. De Benedictis FM, Bush A. Rhinosinusitis and asthma: epiphenomenon or causal association. Chest. 1999;115:550-56.

6. Passalacqua G, Canonica GW. Impact of rhinitis on airway inflammation: biological and therapeutic implications. Respir Res. 2001;2:320-23.

7. Dykewicz MS, Fineman S. Diagnosis and management of rhinitis: complete guidelines of the Joint Task Force on Practice Parameters in Allergy, Asthma, and Immunology. Ann Allergy Asthma Immunol. 1998;81(5 pt 2):478-518.

8. Stempel DA, Woolf R. The cost of treating allergic rhinitis. Curr Allergy Asthma Rep. 2002;2:223-30

9. Blanc PD, Trupin L, Eisner M, et al. The work impact of asthma and rhinitis: findings from a population-based survey. J Clin Epidemiol. 2001;54:610-618.

10. Nash DB, Sullivan SD, Mackowiak J. Optimizing quality of care and costeffectiveness in treating allergic rhinitis in a managed care setting. Am J Manag Care. 2000;6(suppl 1):S3-S15

11. Crystal-Peters J, Crown WH, Goetzel RZ, Schutt DC. The cost of productivity losses associated with allergic rhinitis. Am J Manag Care. 2000;6:373-78.

12. American Lung Association. Trends in asthma morbidity and mortality. Available at: http://www.lungusa.org/data/asthma/asthmal.pdf. Accessed August 28, 2003.

13. American Lung Association. Asthma news. Available at: http://www.lungusa.org/asthma/merck_pressl.html. Accessed August 29, 2003.

14. Beasley R. The burden of asthma with specific reference to the United States. J Allergy Clin Immunol. 2002;109(suppl 5):S482-S489.

15. Managed Care Measures. Respiratory Benchmarks 2001. Marlton, New Jersey: Managed Care Measures, LLC; 2001. 
16. Sinus and Allergy Health Partnership. Antimicrobial treatment guidelines for acute bacterial rhinosinusitis. Otolaryngol Head Neck Surg. 2000;123(1 pt 2):S1-S31. 17. Gwaltney JM Jr. Acute community-acquired sinusitis. Clin Infect Dis. 1996;23:1209-23.

18. Passalacqua G, Ciprandi G, Canonica GW. The nose-lung interaction in allergic rhinitis and asthma: united airway disease. Curr Opin Allergy Clin Immunol. 2001;1:7-13.

19. Spector SL. Overview of comorbid associations of allergic rhinitis. J Allergy Clin Immunol. 1997;99:S773-S780.

20. Skoner DP. Complications of allergic rhinitis. J Allergy Clin Immunol. 2000;105(6 pt 2):S605-S609.

21. Kapsali T, Horowitz E, Togias A. Rhinitis is ubiquitous in allergic asthmatics. J Allergy Clin Immunol. 1999;99:S138.

22. Settipane RJ, Hagy GW, Settipane GA. Long-term risk factors for developing asthma and allergic rhinitis: a 23-year follow-up study of college students. Allergy Proc. 1994;15:21-25.

23. Pedersen PA, Weeke ER. Asthma and allergic rhinitis in the same patients Allergy. 1983;38:25-29.

24. Bresciani M, Paradis L, Des Roches A, et al. Rhinosinusitis in severe asthma. J Allergy Clin Immunol. 2001;107:73-80.

25. Slavin RG. Complications of allergic rhinitis: implications for sinusitis and asthma. J Allergy Clin Immunol. 1998;101(2 pt 2):S357-S360.

26. Guerra S, Sherrill DL, Martinez FD, et al. Rhinitis as an independent risk factor for adult-onset asthma. J Allergy Clin Immunol. 2002;109:419-25.

27. Baraniuk JN. Pathogenesis of allergic rhinitis. J Allergy Clin Immunol. 1997;99:S763-S772.

28. Brugman SM, Larsen GL, Henson PM, Honor J, Irvin CG. Increased lower airways responsiveness associated with sinusitis in a rabbit model. Am Rev Respir Dis. 1993;147:314-20.

29. Littell NT, Carlisle CC, Millman RP, Braman SS. Changes in airway resistance following nasal provocation. Am Rev Respir Dis. 1990;141:580-83.

30. Kaufman J, Chen JC, Wright GW. The effect of trigeminal resection on reflex bronchoconstriction after nasal and nasopharyngeal irritation in man. Am Rev Respir Dis. 1970;101:768-69.

31. Ciprandi G, Pronzato C, Ricca V, Passalacqua G, Bagnasco M, Canonica GW Specific allergen challenge induces ICAM-1 expression on nasal epithelial cells in allergic subjects. Am J Respir Crit Care Med. 1994;150(6 pt 1):1653-59.

32. Busse WW, Calhoun WF, Sedgwick JD. Mechanism of airway inflammation in asthma. Am Rev Respir Dis. 1993;147(6 pt 2):S20-S24

33. Foresi A, Pelucchi A, Gherson G, Mastropasqua B, Chiapparino A, Testi R. Once-daily intranasal fluticasone propionate (200 micrograms) reduces nasal symptoms and inflammation but also attenuates the increase in bronchial responsiveness during the pollen season in allergic rhinitis. J Allergy Clin Immunol. 1996;98:274-82

34. Djukanovic R, Wilson JW, Britten KM, et al. Effect of an inhaled corticosteroid on airway inflammation and symptoms in asthma. Am Rev Respir Dis. 1992;145:669-74.

35. Sedgwick JB, Calhoun WJ, Gleich GJ, et al. Immediate and late airway response of allergic rhinitis patients to segmental antigen challenge. Characterization of eosinophil and mast cell mediators. Am Rev Respir Dis. 1991;144:1274-81.

36. Alvarez MJ, Olaguibel JM, Garcia BE, Airway inflammation in asthma and perennial allergic rhinitis. Relationship with nonspecific bronchial responsiveness and maximal airway narrowing. Allergy. 2000;55:355-62.

37. Gaga M, Lambrou P, Papageorgiou N, et al. Eosinophils are a feature of upper and lower airway pathology in non-atopic asthma, irrespective of the presence of rhinitis. Clin Exp Allergy. 2000;30:663-69.

38. Braunstahl GJ, Kleinjan A, Overbeek SE, Prins JB, Hoogsteden HC, Fokkens WJ. Segmental bronchial provocation induces nasal inflammation in allergic rhinitis subjects. Am J Respir Crit Care Med. 2000;161:2051-57.
39. Polosa R, Ciamarra I, Mangano G, et al. Bronchial hyperresponsiveness and airway inflammation markers in nonasthmatics with allergic rhinitis. Eur Respir J. 2000;15:30-35

40. Bousquet J, van Cauwenberge P, Khaltaev N. ARIA Workshop Group. Allergic rhinitis and its impact on asthma. J Allergy Clin Immunol. 2001;108 (suppl 5):S147-S334.

41. Ramsdale EH, Morris MM, Roberts RS, Hargreave FE. Asymptomatic bronchial hyperresponsiveness in rhinitis. J Allergy Clin Immunol. 1985;75: 573-77.

42. Braman SS, Barrows AA, Decoms HA, et al. Airway hyperresponsiveness in allergic rhinitis. A risk factor for asthma. Chest. 1987;91:671-74.

43. Crimi E, Milanese M, Oddera S, et al. Inflammatory and mechanical factors of allergen-induced bronchoconstriction in mild asthma and rhinitis. J Appl Physiol. 2001;91:1029-34.

44. Adams R, Fuhlbrigge A, Ja F, Weiss S. Intranasal steroids and the risk of emergency department visits for asthma. J Allergy Clin Immunol. 2002;109:636-42.

45. Crystal-Peters J, Neslusan C, Crown W, Torres A. Treating allergic rhinitis in patients with comorbid asthma: the risk of asthma-related hospitalizations and emergency department visits. J Allergy Clin Immunol. 2002;109: 57-62.

46. Grant JA, Nicodemus CF, Findlay SR, et al. Cetirizine in patients with seasonal rhinitis and concomitant asthma: prospective randomized, placebocontrolled trial. J Allergy Clin Immunol. 1995;95(5 pt 1):923-32.

47. Corren J, Harris AG, Aaronson D, et al. Efficacy and safety of loratadine plus pseudoephedrine in patients with seasonal allergic rhinitis and mild asthma. J Allergy Clin Immunol. 1997;100(6 pt 1):781-88.

48. Welsh PW, Stricker WE, Chu CP, et al. Efficacy of beclomethasone nasal solution, flunisolide, and cromolyn in relieving symptoms of ragweed allergy. Mayo Clin Proc. 1987;62:125-34.

49. Mygind N, Dahl R, Nielsen LP. Effect of nasal inflammation and of intranasal anti-inflammatory treatment on bronchial asthma. Respir Med. 1998:92:547-49.

50. Corren J, Adinoff AD, Buchmeier AD, Irvin CG. Nasal beclomethasone prevents the seasonal increase in bronchial responsiveness in patients with allergic rhinitis and asthma. J Allergy Clin Immunol. 1992;90:250-56.

51. Aubier M, Levy J, Clerici C, Neukirch F, Herman D. Different effects of nasal and bronchial glucocorticosteroid administration on bronchial hyperresponsiveness in patients with allergic rhinitis. Am Rev Respir Dis. 1992;146 $122-26$.

52. Watson WT, Becker AB, Simons FE. Treatment of allergic rhinitis with intranasal corticosteroids in patients with mild asthma: effect on lower airway responsiveness. J Allergy Clin Immunol. 1993;91(1 pt 1):97-101.

53. Fuhlbrigge AL, Adams RJ. The effect of treatment of allergic rhinitis on asthma morbidity, including emergency department visits. Curr Opin Allergy Clin Immunol. 2003;3:29-32.

54. Gelfand EW, Cui ZH, Takeda K, Kanehiro A, Joetham A. Fexofenadine modulates T-cell function, preventing allergen-induced airway inflammation and hyperresponsiveness. J Allergy Clin Immunol. 2002;110:85-95.

55. Baena-Cagnani CE. Desloratadine activity in concurrent seasonal allergic rhinitis and asthma. Allergy. 2001;56(suppl 65):21-27.

56. Aubier M, Neukirch C, Peiffer C, Melac M. Effect of cetirizine on bronchial hyperresponsiveness in patients with seasonal allergic rhinitis and asthma. Allergy. 2001;56:35-42

57. Roquet A, Dahlen B, Kumlin M, et al. Combined antagonism of leukotriene and histamine produces a predominant inhibition of allergeninduced early and late phase airway obstruction in asthmatics. Am J Respir Crit Care Med. 1997;155:1856-63.

58. Nelson HS. Prospects for antihistamines in the treatment of asthma. J Allergy Clin Immunol. 2003;112(suppl 4):S96-S100

59. Lee DK, Bates CE, Currie GP, Lipworth BJ. Comparative in vivo bioactivity of modern $\mathrm{Hl}$-antihistamines on AMP challenge in atopic asthma. J Allergy Clin Immunol. 2003;111:337-41. 
60. Borish L. The role of leukotrienes in upper and lower airway inflammation and the implications for treatment. Ann Allergy Asthma Immunol. 2002;88 (4 suppl 1):16-22.

61. Creticos PS, Peters SP, Adkinson NF Jr., et al. Peptide leukotriene release after antigen challenge in patients sensitive to ragweed. N Engl J Med. 1984; 310:1626-30

62. Wilson AM, O'Byrne PM, Parameswaran K. Leukotriene receptor antagonists for allergic rhinitis: a systematic review and meta-analysis. Am J Med. 2004;116:338-44.

63. Nathan RA. Pharmacotherapy for allergic rhinitis: a critical review of leukotriene receptor antagonists compared with other treatments. Ann Allergy Asthma Immunol. 2003;90:182-90.

64. Wilson AM, Orr LC, Sims EJ, et al. Antiasthmatic effects of mediator blockade versus topical corticosteroids in allergic rhinitis and asthma. Am J Respir Crit Care Med. 2000;162(4 pt 1):1297-1301.
65. Meltzer EO, Ehrlich PM. A step approach to the clinical management of allergic rhinitis: prescription and over-the-counter therapeutic reference summary. Manag Care Interface. 1999;12:70-77.

66. Rachelefsky GS, Katz RM, Siegel SC. Chronic sinus disease with associated reactive airway disease in children. Pediatrics. 1984;73:526-29.

67. Friedman R, Ackerman M, Wald E, Casselbrant M, Friday G, Fireman P. Asthma and bacterial sinusitis in children. J Allergy Clin Immunol. 1984;74: 185-89.

68. Nishioka GJ, Cook PR, Davis WE, et al. Functional endoscopic sinus surgery in patients with chronic sinusitis and asthma. Otolaryngol Head Neck Surg. 1994;110:494-500.

69. Park AH, Lau J, Stankiewicz J, et al. The role of functional endoscopic sinus surgery in asthmatic patients. J Otolaryngol. 1998;27:275-80. 